\title{
Serum Levels of Soluble Forms of T Cell Activation Antigens CD27 and CD25 in Systemic Lupus Erythematosus in Relation with Lymphocytes Count and Disease Course
}

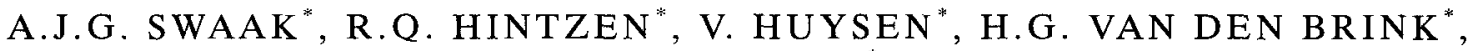 \\ J.T. SMEENK ${ }^{*}$
}

\begin{abstract}
Summary Systemic lupus erythematosus (SLE) patients are characterized by a low lymphocyte count, which is considered a specific disease marker and is related to disease activity. The membrane bound molecules CD25 and CD27 are expressed and released in a soluble $\mathrm{CD} 25$ ( $\mathrm{SCD25}$ ) and soluble CD27 (sCD27) form by activation of predominantly $T$ cells. In previous studies it was claimed that sCD25 as well sCD27 might be used as parameters for activation of the immune system; a correlation between the SCD25 profile with the disease course in SLE patients was also shown.

To assess the relationship between lymphocyte count and these $T$ cell activation markers, we performed a cross-sectional and a longitudinal study. In the longitudinal study three SLE patients who were known for a long time at our outpatient clinic were studied. Both $T$ cell markers strongly correlated with each other and formed a reflection of the disease course. In all 7 periods of exacerbation, which we observed in the 3 investigated patients, both levels increased preceding this period; however, no correlation was found with the lymphocyte count. In the cross sectional study of 69 patients with SLE, SCD25 and SCD27 levels were correlated with defined disease manifestations; $\mathrm{SCD} 25$ was elevated in all periods of increased

- disease activity. The same holds true for $\mathrm{SCD27}$, with the exception of patients with nephritis in which the highest levels were observed. Both profiles of $\mathrm{sCD} 25$ and sCD27 were strongly correlated during the whole disease course. Our data prove that in the pathogenesis of SLE an active recruitement of unprimed and primed $T$ cells takes place.
\end{abstract}

Key words Systemic Lupus Erythematosus, Soluble CD25, Soluble CD27, Disease Activity

\section{INTRODUCTION}

Quantification of products of T-lymphocyte activation could be one method of monitoring disease activity in systemic lupus erythematosus (SLE). T-lymphocyte activation requires induction of Interleukin-2 (IL-2) as well as its receptor (IL-2R) $(1,2)$. Activation of T-cells leads

The Central Laboratory of the Netherlands Red Cross blood transfusion Service and laboratory for Experimental and Clinical Immunology, University of Amsterdam, The Netherlands and the

'Department of Rheumatology, Dr Daniel den Hoed Clinic, Rotterdam, The Netherlands. to secretion of IL-2 but also a truncated form of its receptor, $10 \mathrm{kD}$ smaller than the $55-65 \mathrm{kD}$ membrane bound protein, will be released $(3,4)$. The rate of release of this molecule (soluble CD25) is in proportion to its cell surface expression $(4,5)$. Serum levels of soluble CD25 are claimed to correlate with disease activity in patients with SLE (6).

Recently another $\mathrm{T}$ cell membrane molecule CD27 was described. Activation of $\mathrm{T}$ cells by the T-cell receptor $\mathrm{CD} 3(\mathrm{TCR} / \mathrm{CD} 3)$ complex induces a strong increase of CD27 membrane expression, predominantly on naive CD45 RA+ cells with a concomittant release of a 28$32 \mathrm{kD}$ form of CD27 in the supernatant (soluble CD27) 
(8-10). Till now the functions of soluble CD25 (sCD25) and soluble $\mathrm{CD} 27$ (sCD27) are uncertain, but both may have an immunoregulatory role.

Elevated levels of sCD27 have been shown in sarcoidosis during acute CMV and HIV infections, in synovial fluid of rheumatoid arthritis patients and in cerebrospinal fluid of multiple sclerosis patients $(11,21)$. Furthermore, evidence is obtained that $\mathrm{sCD} 27$ is not released by cells lacking CD27 membrane expression. Cells that could produce $\mathrm{SCD} 27$ were either CD45 $\mathrm{RA}^{+}$or CD45 $\mathrm{RO}^{+}$, which would indicate that elevated titers of $\mathrm{sCD} 27$ are a reflection of active recruitement of the unprimed and primed T-cell pool, rather than an expansion of the fully differentiated CD45 RA-CD27- T cells (22). Measurement of sCD27 in relation to sCD25 might therefore be useful for obtaining insight into the type of cell that is activated during the disease course of patients with SLE.

A remarkable finding in SLE is the occurrence of lymphopenia which is reported in $75 \%$ of untreated patients. Its presence is claimed to correlate with disease activity $(23,24)$. The cause of lymphopenia remains unclear, a suggestion could be that lymphopenia is more or less a reflection of an increased cell turnover. If $\mathrm{sCD} 25$ and sCD27 are markers for T-cell activation, one might wonder if between the degree of T-cell activation and the existence of lymphopenia a relation exists.

Most studies in SLE patients relating immunological parameters (like sCD25) with disease activity, have a cross sectional character or are confined to a small number of patients followed over a short period of time. Hardly ever are the investigated parameters studied in the same patient with different disease periods characterized by more or less the same disease activity, in order to obtain insight into the reproducibility of the obtained correlations.

From 1970 all SLE patients known at our institute were followed according to fixed protocols to obtain clinical data and sera samples. At this moment it was possible to make a selection of patients with a disease duration of more than a decade. A selection of 3 SLE patients, who were known at our institute for such a long time period was made.

The aim of this study was to evaluate profiles of both T-cell activation markers (sCD25 and sCD27) in relation to each other and to the disease course in three SLE patients. Also in these three extensive longitudinal studies the interrelationship between the profiles of sCD25 and $\mathrm{SCD} 27$ was studied in regard to lymphocyte levels. Furthermore, these T-cell activation markers were studied in a cross sectional study in 69 SLE patients with defined clinical symptoms.

\section{MATERIALS AND METHODS}

\section{Longitudinal study}

From the start of our studies in 1970 clinical data, from all patients fulfilling the ARA criteria (19), were recorded using well defined protocols. At that time different prospective studies were started to elucidate the diagnostic significance of anti double-stranded DNA (antidsDNA) (20), and the prognostic significance of antidsDNA $(20,21)$. This permitted us now to evaluate prospectively the disease course of patients who were followed and chosen for this study. Three patients who were followed over a long period of time with different disease courses and outcomes were analysed. From these patients all clinical data for evaluation, and also series of regularly sampled sera were available. The different disease courses of the patients were divided into periods of minor and major disease symptoms as described previously $(6,20,21)$. This enabled us to compare different disease periods within the same patient, but also with those of the other patients. Minor symptoms are mainly restricted to the musculo- skeletal system and the skin and may be controlled by an increase of prednisolone dosage of $5-15 \mathrm{mg} /$ day without the need for admission to hospital. Major symptoms are characterized by at least one of the following manifestations: renal impairment, serositis, anaemia (haemoglobulin $<110 \mathrm{gr} /$ L) and/or leucopenia (white blood cell count $<4 \times 10$ 9/L) and/or thrombocytopenia (platelet count $<50 \times 10$ $9 / \mathrm{L}$ ), neurological or psychiatric symptoms, treated with prednisolone dosage of more than $20 \mathrm{mg}$ daily with admission to the hospital. All cases in which the symptoms were explained by causes other than SLE were excluded.

\section{Patients}

Patient HA, female, born in 1956, developed a symmetrical polyarthritis in 1982. In May 1984 she was admitted to the hospital with temperature and fatigue. Routine laboratory examination revealed a proteinuria $(>$ $3.5 \mathrm{gr} / \mathrm{L}$ ) and positive $\mathrm{LE}$ cell preparation confirming the diagnosis of SLE. From that time she was followed at our outpatient clinic. A pleuro-pericarditis combined with leucocytopenia developed in 1986 in addition to a decrease in renal function to $45 \mathrm{ml} / \mathrm{min}$. (GFR). Treatment was started with azathioprine $(150 \mathrm{mg} /$ day $)$ and prednisolone (20 mg/day). She was well till June 1986, when she slowly developed periods of temperature and increasing feeling of fatigue. Admission to the hospital took place in November 1987 with a serious skin vascu- 
litis, and periods of unconciousness. After institution of treatment she recovered and the clinical signs subsided. In the following years, the disease course was stable until April 1990 when a further deterioration in renal function took place with the same symptoms of periods of unconciousness as in 1988.

Patient Bo, female, born in 1937, was for the first time admitted to the hospital in June 1980 with clinical signs of a pleuro-pericarditis and a detoriation of renal function. Renal biopsy showed the picture of a diffuse proliferative glomerulonephritis. Serological examination revealed the existence of ANA and the diagnosis of SLE was made. She was feeling well till August 1982, when she developed pneumonia, which was treated with ampicilline and for a short time the prednisolone dose was increased to $20 \mathrm{mg} /$ day. From that time the disease course was stable with only periods of musculoskeletal and skin symptoms. In July 1989 she developed alopecia with increasing complaints of fatigue and temperature. Other clinical signs were not found, but to improve her general feeling she was treated for a short period with high doses of prednisolone ( $40 \mathrm{mg}$ /day for six weeks). She suffered mostly of depression. At the end of 1990 nailfold lesions developed, signs of her depression worsened, in combination with a detoriation of the renal function. In September 1990 she was admitted to the hospital with the diagnosis of organic-psychosyndrome, nephritis, and pleuritis.

Patient Hey, female, born in 1952, showed in 1982 signs of polyarthralgia. Clinical examination revealed a hypofunction of the thyroid gland. On serological examination anti-nuclear antibodies were detected. In June 1983 she developed a period of thrombocytopenia $(<50 \mathrm{x}$ 10/9) accompanied by a decrease in haemoglobin with a positive Coombs reaction. From that the diagnosis of SLE was made and the patient was followed at our outpatient clinic. In December 1985, she developed pneumonia and sputum examination showed the existence of legionella. She recovered and was well till September 1989 when at routine examination it became evident that a proteinuria ( $<3.5 \mathrm{gr} /$ day) developed slowly. Renal biopsy showed the picture of mesangial proliferative glomerulonephritis. Treatment with prednisolone was refused. In 1990, skin rashes, periods of temperature with a further increase in proteinuria, as also a decrease in glomerular filtration rate took place. Again at this moment she refused treatment with prednisolone but treatment with azathioprine was instituted.

\section{Cross sectional study}

From the large group of SLE-patients, known at our lupus outpatient clinic, 4 groups of patients were select- ed. The selection criterion was the availability of a serum sample during an exacerbation of their disease. Group A consisted of 20 SLE-patients with an exacerbation in which they showed signs of active nephritis. Patients with pre-established renal involvement were considered to be inactive when no significant alteration took place in the serum creatinine values, proteinuria, urine sediment or blood presure. Renal function was assumed to have deteriorated when proteinuria increased at least $1 \mathrm{gr} / 24 \mathrm{~h}$ and/or when there was an increase in red blood cell count in the urinary sediment or a decrease in glomerular filtration rate (GFR) of more than $20 \%$. Increases in urinary protein, sediment abnormalities, or decreases in GFR were considered significant only if observed on at least three consecutive days. An increase in proteinuria or other indications of a further deterioration of renal function in the absence of other causes (such as pyelonephritis) not being related to SLE were indicative for renal disease.

Group B consisted of 12 selected sera of patients who during an exacerbation only showed signs of central nervous system (CNS) involvement. CNS involvement was diagnosed when seizures, coma or changes in mental status in the absence of drugs or other known metabolic causes occurred (22). For psychosis, the same criteria were used as described earlier (23).

Group C consisted of 12 SLE-patients who during an exacerbation only showed signs of a pleuritis and/or pericarditis. Pleuritis was defined as painful in- and experium with, on auscultation, a pleuritic rub and/or a pleura effusion. Pericarditis was defined by typical findings on auscultation (pericardial rub), characteristic electrocardiographic abnormalities or by signs of pericardial effusion observed on X-ray or echocardio-graphic examination.

Group D consisted of 25 SLE patients who during a period showed haematological signs characterised by at least one or more of the following manifestations: anaemia $(\mathrm{Hb}<7 \mathrm{mMol} / \mathrm{L})$ and/or leucopenia (WBC $<4 \times 10$ $9 / \mathrm{L}$ ) and/or thrombocytopenia (platelet count $<50 \times 10$ 9/L).

\section{Soluble CD27 (sCD27) and CD25 (sCD25) assays}

sCD27 levels were measured as described (10). In brief, 96-well plates (Maxisorp, Nunc, Denmark) were coated with $100 \mathrm{ul}$ of a monoclonal antibody to $\mathrm{CD} 27(\mathrm{mAb})$ (CLB-CD27/3; $4 \mathrm{ug} / \mathrm{ml}$ ) in PBS (pH 7.4) per well for two hours at $37^{\circ} \mathrm{C}$. Non-specific binding sites in the wells were blocked by incubation at $37^{\circ} \mathrm{C}$ with PBS containing $1 \%$ normal goat serum and $0,1 \%$ Tween-20. All further steps were performed using this buffer, unless otherwise specified. The wells were then washed and filled 
with $100 \mathrm{ul}$ of sample dilutions in PBS, $0.1 \%$ Tween-20, $10 \mathrm{mMol}$ EDTA and incubated overnight at $4^{\circ} \mathrm{C}$. After washing, $100 \mathrm{ul}$ of biotinylated mAb CLB-CD27/1 $(1 \mathrm{ug} / \mathrm{ml})$ was incubated for 1 hour at $37^{\circ} \mathrm{C}$. After washing, a 1:2000 dilution of Avidine-Peroxidase (Sigma) was added and incubated for 1 hour at $37^{\circ} \mathrm{C}$. After washing,

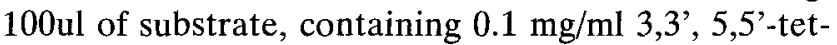
ramethylbenzidine (Merck, Darmstadt, FRG) and 0.06\% hydrogen peroxide dissolved in 0.1 M Sodium Acetate buffer ( $\mathrm{pH} 5.5$ ), were added to the wells and after $15^{\prime}$ the peroxidase reaction was stopped by adding $50 \mathrm{ul}$ of $2 \mathrm{~N} \mathrm{H} 2 \mathrm{SO} 4$ and the absorbance at $450 \mathrm{~nm}$ was determined with a Titertek ELISA reader (Flow Laboratories, Rockville, MD). The concentrations of $\mathrm{sCD} 27$ were expressed as units $/ \mathrm{ml}(\mathrm{U} / \mathrm{ml})$, by reference to a standard curve that was constructed from absorbance values of serial dilutions of pooled supernatants of PBMC stimulated for 3 days with phytohemagglutinin $(1 \mathrm{ug} / \mathrm{ml})$. The amount of sCD27 present in this standard was arbitrarily set at $100 \mathrm{U} / \mathrm{ml}$.

sCD25 was quantitated with an ELISA similar to the sCD27 assay, but now using MAb 7G7B6 (4ug/ml), that was obtained from the ATCC, as coating antibody and biotin labeled CLB-CD25/1 $(0.5 \mathrm{ug} / \mathrm{ml})$ as conjugate. sCD25 units were related to the standard provided with a commercially available sCD25 ELISA kit (T Cell Sciences, Cambridge, MA). The lower detection limits of both assays were $50 \mathrm{U} / \mathrm{ml}$. The intra- and interassay variation coefficients of the ELISA were $8.4 \%$ and $9.4 \%$ respectively $(n=42)$.

\section{Sera}

Serum was separated from freshly drawn blood and stored at $-20^{\circ} \mathrm{C}$. In initial experiments it was ascertained that repeatedly freezing and/or thawing had no effect on the levels of sCD25 and sCD27. The lymphocyte count was derived from the total peripheral leucocyte differential counts, which was performed in the clinical laboratory of the hospital.

\section{RESULTS}

\section{sCD25 and SCD27 profiles in relation to the disease course in three prospectively followed SLE-patients}

In total 7 exacerbations were observed in the investigated three patients who were followed over a period of 26 patient years. Examples of the profiles during periods with major symptoms are presented in Figs. 1 and 2 . These observations are illustrative of all 7 periods, showing an increase in the serum levels of both SCD25 and SCD27, which dropped when the patient recovered and treatment was installed. That both profiles of sCD25 and sCD27 were comparable was illustrated by plotting them against one another (Fig. 3); a strong correlation was found between individual serum values.

During the periods that the patients had a stable disease course, the levels remained more or less the same, never reaching such levels as observed when the patients developed their exacerbations as illustrated in Figs. 1 and 2 .

\section{Lymphocyte count in relation to the $\mathrm{SCD25}$ and sCD27 profiles in the three disease courses}

Between the different profiles in the three patients some correlations could be observed (Table I). In the period preceding an exacerbation the lymphocyte count which overall had decreased remained stable; in 3 periods they decreased further. In the period of major disease symptoms, the sCD25 and sCD27 levels decreased; in two periods a further decrease of the lymphocyte count concomitantly took place, but overall the lymphocyte levels increased as illustrated in Figs. 1 and 2.

These observations suggest a correlation between the lymphocyte count and the levels of sCD25 and sCD27, but a statistical significance could not be calculated between the absolute values.

\section{Levels of SCD25 and sCD27 at the moment of major symptoms (cross sectional study)}

The results obtained in the cross-sectional study, in which the parameters were investigated during the period of exacerbation, are shown in Table II and Fig. 4.

Regarding the sCD25 levels no difference could be calculated between the different groups of patients. For sCD27 clearly significant differences were calculated between CNS involvement and nephritis $\left(\mathrm{P}<3.610^{-4}\right)$ and pleuro-pericarditis $\left(\mathrm{P}<4.910^{-2}\right)$. Overall the highest levels were detected in the nephritis group of $\mathrm{sCD} 25$ and sCD27. Between the serum levels of sCD25 and sCD27 and anti-dsDNA no correlation could be demonstrated (data not shown). However, all SLE-patients at the moment of serum sampling showed increased levels of SCD25 as well as sCD27 compared with the levels in normals.

\section{DISCUSSION}

Stimulation of T-cells can be monitored by measuring the produced cytokines or by analysis of soluble membrane antigens that are released by these cells, like soluble CD25 and CD27. The detection in serum of such 


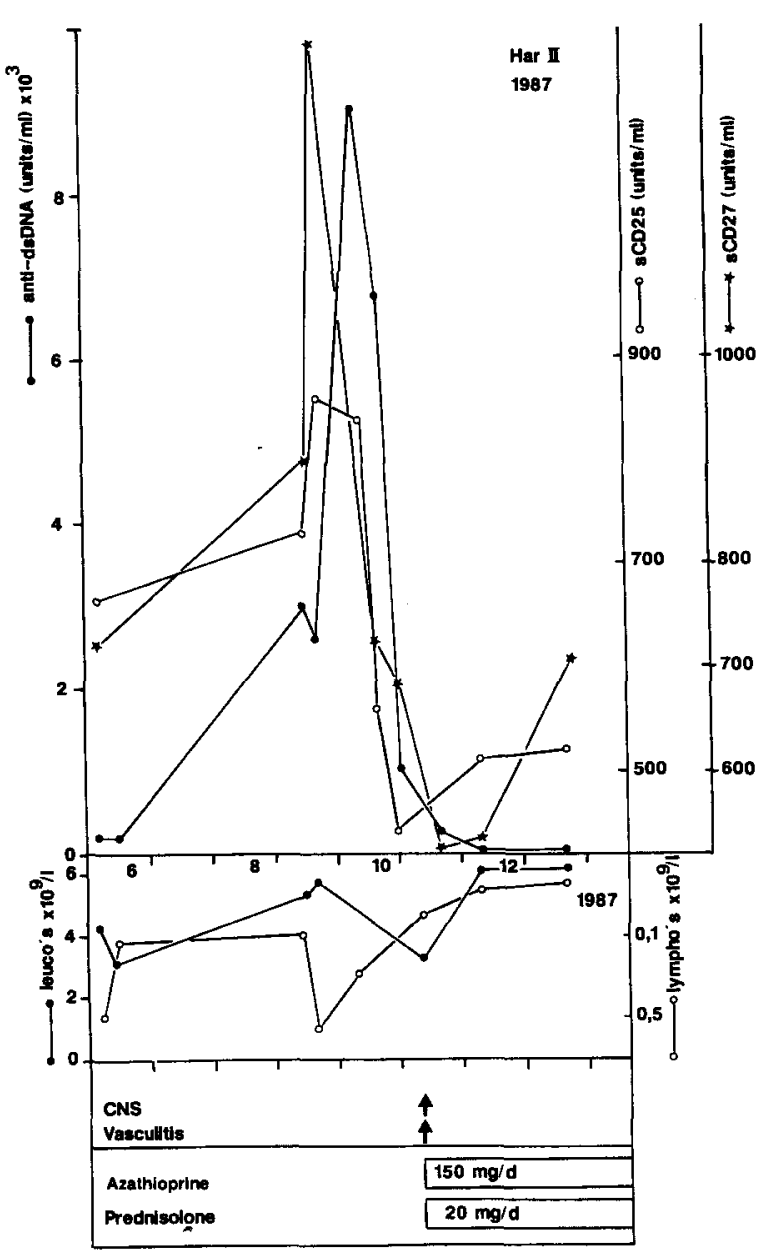

Fig. 2: During the disease course (1990) of patient Bo an exacerbation developed with mainly symptoms of an organic psychosyndrome. This period was preceded by an increase in the levels of anti-dsDNA, SCD25 and $\mathrm{SCD} 27$. The lymphocyte count was low during the whole disease period and increased slightly after the exacerbation and institution of treatment.

Fig. 1: In the clinical disease course (1987) patient Ha developed an exacerbation of her disease. This period was preceded by an increase in the anti-dsDNA levels as well of sCD25 and cCD27. Overall a decreased lymphocyte count was observed, which dropped preceding the exacerbation and thereafter increased already before the institution of treatment.

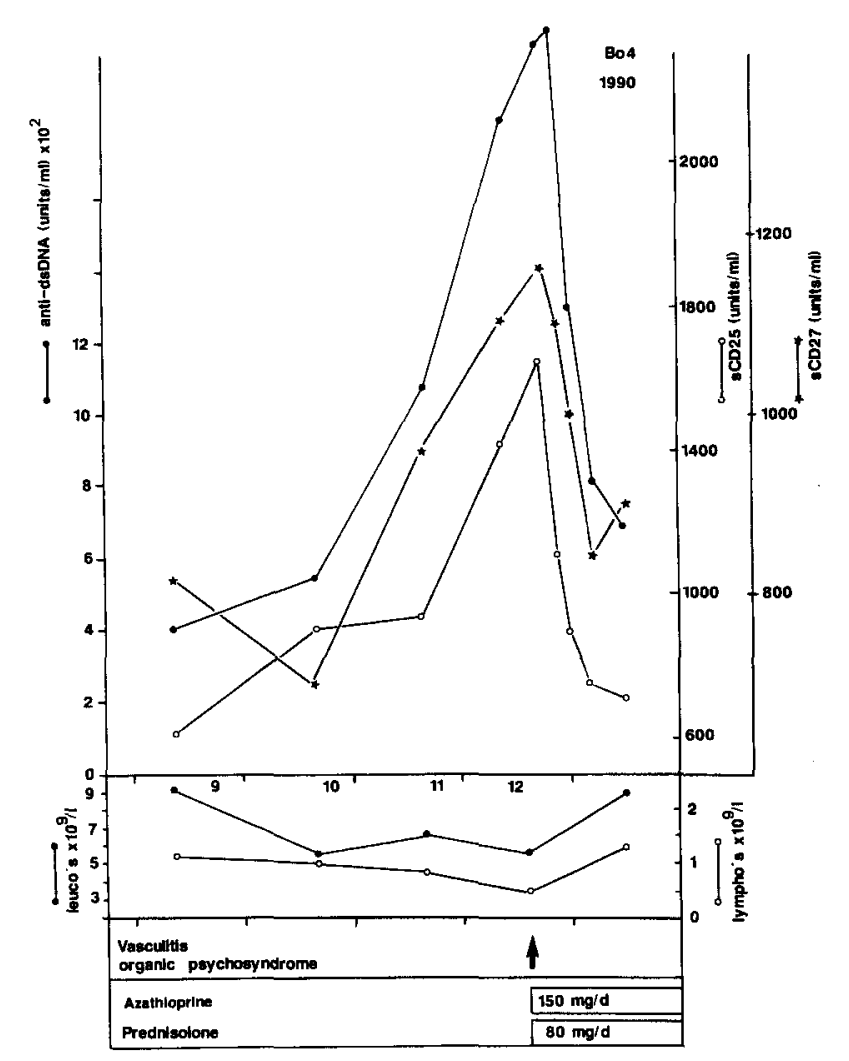




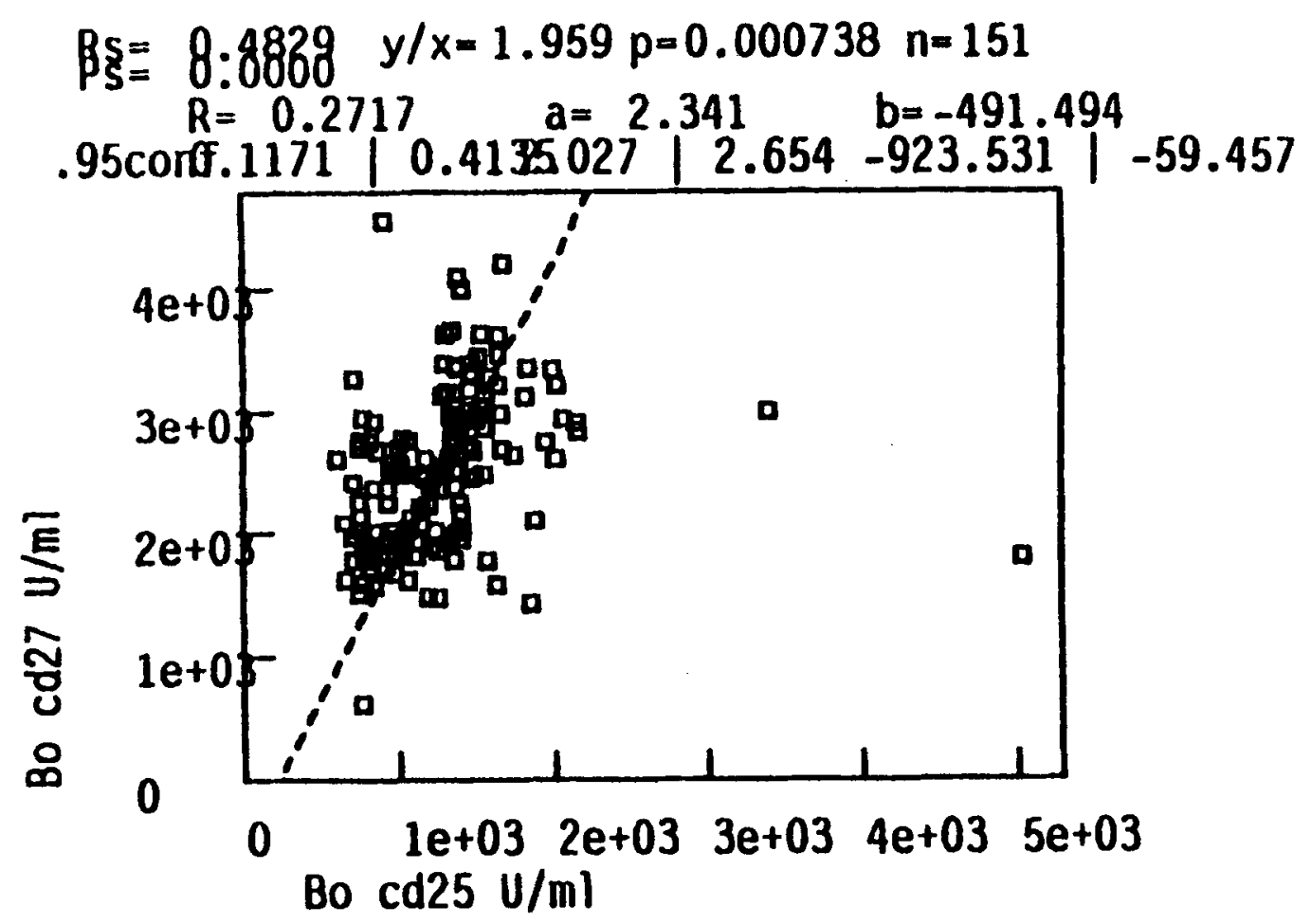

Fig. 3: $\mathrm{sCD} 25$ and $\mathrm{sCD} 27$ are plotted against one another, in an attempt to see whether the correlation observed in patient $\mathrm{B}$ was also found when all individual sera samples were compared. Between both T-cell activation markers a strong correlation could be calculated ( $\mathrm{p}=0.000738$ ).

Table I: Relationship between disease course (major disease symptoms) with the lymphocyte count profile and T-cell activation markers (sCD25, sCD27)

\begin{tabular}{|c|c|c|c|c|c|c|c|}
\hline \multirow[b]{2}{*}{ Pat. } & \multirow[t]{2}{*}{ Periods } & \multicolumn{3}{|c|}{ Preceding } & \multicolumn{3}{|c|}{ During/After } \\
\hline & & $\begin{array}{c}\text { Lymphoc.* } \\
\text { count }\end{array}$ & sCD25 & sCD27 & $\begin{array}{c}\text { lymphoc. } \\
\text { count }\end{array}$ & $\mathrm{sCD} 25$ & sCD27 \\
\hline \multirow[t]{3}{*}{$\overline{\mathrm{HA}}$} & $1985 / 86$ & 0 & $T$ & $T$ & $\downarrow$ & $\downarrow$ & $\downarrow$ \\
\hline & 1987 & 0 & $\uparrow$ & $\uparrow$ & $\uparrow$ & $\uparrow$ & $\downarrow$ \\
\hline & 1990 & $\downarrow$ & $\uparrow$ & $\uparrow$ & $\uparrow$ & 0 & $\downarrow$ \\
\hline \multirow[t]{2}{*}{ BO } & 1989 & $\downarrow$ & $\uparrow$ & $\uparrow$ & $\uparrow$ & $\downarrow$ & $\downarrow$ \\
\hline & 1990 & $\downarrow$ & $\uparrow$ & $\uparrow$ & $\uparrow$ & $\downarrow$ & $\downarrow$ \\
\hline \multirow[t]{2}{*}{ HEY } & 1989 & 0 & $\uparrow$ & $\uparrow$ & $\downarrow$ & $\downarrow$ & $\downarrow$ \\
\hline & 1990 & 0 & $\uparrow$ & $\uparrow$ & $\uparrow$ & $\downarrow$ & $\downarrow$ \\
\hline
\end{tabular}

A* A change in lymphocyte counts was defined as an alteration of more than $20 \%$ during the observation period.

Values were evaluated during 3 months before (period preceding exacerbation) and thereafter (period during and after exacerbation).

$0=$ no change; $\uparrow$ or $\downarrow$ is a change of the separate values as defined.

Table II: Serum levels of SCD25 and SCD27 at the moment of major disease symptoms

\begin{tabular}{|c|c|c|c|c|c|}
\hline \multirow{4}{*}{$\begin{array}{l}\text { Major symptoms } \\
\text { Nephritis }\end{array}$} & \multicolumn{5}{|c|}{ serum levels (units)/ml) } \\
\hline & \multicolumn{3}{|c|}{$\mathrm{sCD} 25$} & \multicolumn{2}{|c|}{$\mathrm{sCD} 27$} \\
\hline & Nos & Median & range & Media & range \\
\hline & 20 & 982 & 680 & 609 & 302 \\
\hline CNS involvement & 12 & 862 & 671 & 314 & 164 \\
\hline Pleurocarditis & 12 & 1044 & 572 & 531 & 275 \\
\hline $\begin{array}{l}\text { Haematological } \\
\text { symptoms }\end{array}$ & 25 & 796 & 601 & 789 & 833 \\
\hline $\begin{array}{l}\text { Normal blood bank } \\
\text { donors }\end{array}$ & 20 & 310 & 114 & 186 & 103 \\
\hline
\end{tabular}

Table III: Reported serum levels of soluble CD25 and CD27 in healthy controls

\begin{tabular}{llll}
\hline Author & Ref & Nos & sCD27 (range) \\
Hintzen (1991) & 10 & 55 & $105-210$ \\
Swaak (1994) & - & 20 & $110-390$ \\
& & & sCD25 (mean +/-) \\
Wolf (1992) & 25 & 30 & $197-22$ \\
Ward (1991) & 26 & 10 & $235-84$ \\
Airo (1991) & 27 & 19 & $301-90$ \\
Raziuddin (1991) & 28 & 64 & $212-18$ \\
Swaak (1994) & - & 20 & $310-114$ \\
\hline
\end{tabular}




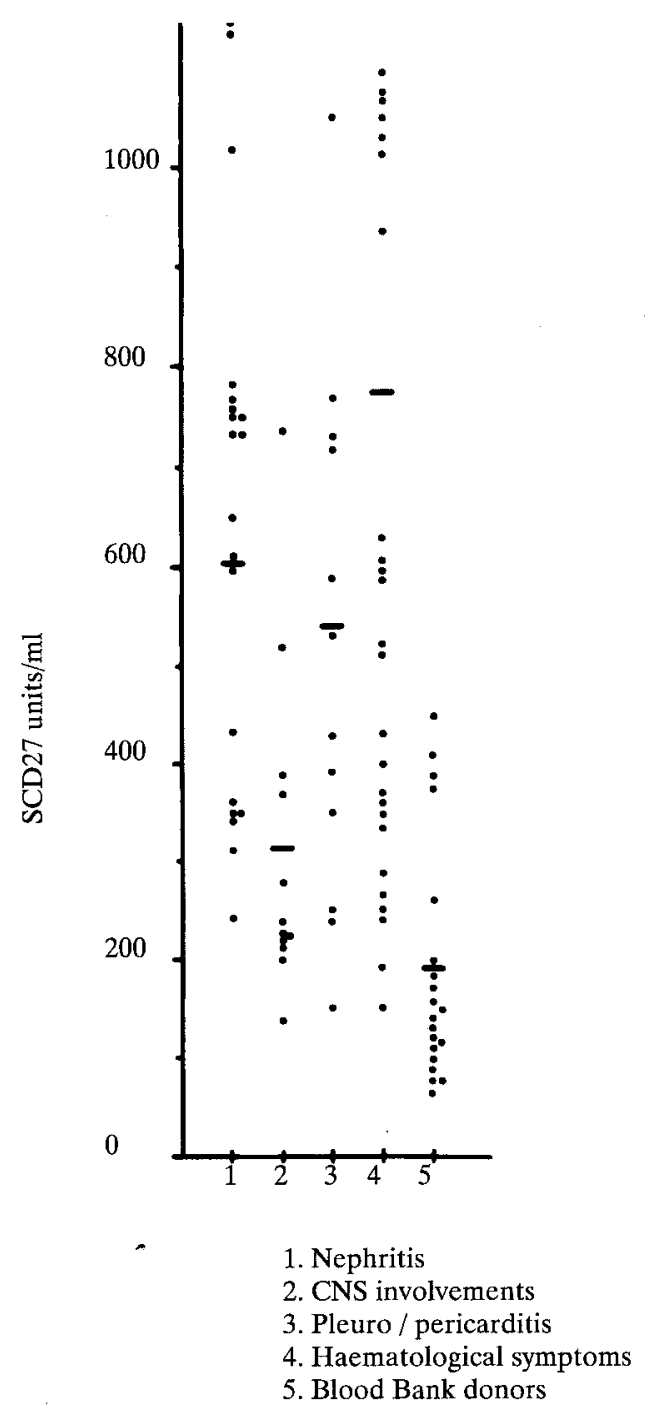

Fig. 4: Serum levels of sCD27 at the moment of defined major disease symptoms in systemic lupus erythematosus patients.

markers for activated $\mathrm{T}$ lymphocytes might be useful to monitor the disease-course and eventually to evaluate the response to therapy in patients with SLE. Our data showed that in SLE both soluble T cell markers, SCD25 and $\mathrm{SCD} 27$, are elevated. This was not only the case during an exacerbation, but also when the patients had a rather stable disease course. The profiles of SCD25 and sCD27 were the same and both levels were strongly correlated with each other. In relation to specific disease manifestation, differences were only noted in the levels of sCD27. The highest levels were found in patients with a nephritis, the lowest levels in patients with CNS involvement. The profiles of both $\mathrm{T}$ cell markers and the
anti-dsDNA profile showed the same picture. Periods of exacerbation were mostly heralded by a low lymphocyte count $(<1.5 \times 109 / 1)$. In a period of 3 months before the clinical manifestations of an exacerbation a further decrease took place, in the period of the presence of major symptoms and thereafter the levels increased mostly (Table II). Between the lymphocytes count and the separate levels of sCD27 ad sCD25 no correlation could be calculated. Our results of the levels of sCD25 and sCD27 are in accordance with those reported in the literature. A short survey is given in Table III. Recent studies (6, 24,27 ) have demonstrated that levels of sCD25 are elevated in SLE. When comparing levels between patients with active and inactive disease, significantly higher levels were described in patients with active disease $(24,28)$. The relation between the anti-dsDNA and sCD25 profiles are conflicting, a positive (6) and negative (26) correlation is described. Still, overall sCD25 levels were elevated compared with healthy individuals and correlated to some extent with the levels of anti-dsDNA.

Our cross sectional study and the observations in 3 patients who were followed over a long time period with different periods of major disease manifestations showed that sCD25 as well sCD27 levels correlated well with disease activity. The strong correlation between both serum levels of $\mathrm{sCD} 25$ and $\mathrm{SCD} 27$ sustained that they are representative serological markers for generalized lymphocyte activation.

Despite the mentioned reports as well as our results of the high specificity for disease activity, it should be mentioned that various infectious processes can also cause elevated sCD25 levels $(15,29)$.

In the longitudinal study of three SLE-patients we also wanted to investigate the possible relationship between the lymphocyte count and the $T$ cell markers and diseaseactivity. At this moment, the mechanism of the low lymphocyte count in SLE is poorly understood and different mechanisms are proposed. Our aim was to find a possible correlation between T-cell activation markers and the amount of circulating lymphocytes, which might suggest an increased cell turnover. Between the separate levels no correlation could be calculated, but between the disease course and the lymphocyte count in most instances a relationship was shown.

In conclusion, $\mathrm{sCD} 25$ and $\mathrm{SCD} 27$ are a reflection of $\mathrm{T}$ cell activation present in our patients before and during an exacerbation. Both levels are increased. Our observations also show that in a long time period preceding the clinical manifestations of an exacerbation T- cell activation is going on. 


\section{REFERENCES}

1. Smith, K.A. Interleukin-2: inception, impact and implications. Science $1988,240,1169-1176$.

2. Smith, K.A. Interleukin-2. Sci Am 1990, 262, 50-57.

3. Nelson, D.L., Kurman, C.C., Fritz, M.E., Boutin, B., Rubin, L.A. Production of soluble and cellular Interleukin-2 receptors by cord blood mononuclear cells following in vitro activation. Pediatr Res $1986,20,136$.

4. Rubin, L.A., Jay, G., Nelson, D.L. The released Interleukin-2 receptor binds Interleukin-2 efficiently. J Immunol 1986, 137, 3841.

5. Symons, J.A., Wood, N.C., Di Giovine, F.S., Dull, G.W. Soluble IL-2 receptor in rheumatoid arthritis. J Immunol 1988, 8, 26122618.

6. ter Borg, E.J., Horst, G., Limburg, P.C., Kallenberg, C.G.M. Changes in plasma levels of Interleukin-2 receptor in relation to disease exacerbation and levels of anti-dsDNA and complement in systemic lupus erythematosus. Clin Exp Immunol 1991, 82, 21-26.

7. Swaak, A.J.G, Groenwold, J., Aarden, L.A., Statins van Eps, L.W., Feltkamp, T.E.W. Prognostic value of anti-dsDNA in systemic lupus erythematosus. Ann Rheum Dis 1982, 41, 388-395.

8. van Lier, R.A.W, Borst, J., Vroom, Th.M., Klein., H., van Mourik, P., Zeylemaker, W.P., Melief, C.J.M. Tissue distribution and functional properties of Tp 55 (CD27) A novel T cell differentiation antigen. J Immunol 1987, 139, 1589-1596.

9. de Jong, R., Loenen, W., Brouwer, M., van Emmerik, L., de Vries, E.F.R, Borst, J., van Lier, R.A.W. Regulation of expression of CD27, a $T$ cell specific member of a novel family of membrane receptors. J Immunol 1991, 146, 2488-2494.

10. Hintzen, R.Q., de Jong, R., Hack, C.E., Chamuleau, M., de Vries, E.F.R, van Berge I.J.M, Borst, J., van Lier, R.A.W. A soluble form of the human $T$ cell differentiation antigen. CD27 is released after triggering of the T cell receptor/CD3 complex. J Immunol 1991, $147,29-35$

11. De Jong, R. Activation and function of human T lymphocyte subsets. Thesis University Amsterdam 1992.

12. Hol, B.E.A., Hintzen, R.Q., van Lier, R.A.W, Alberts, P.C., Out, T.A., Jansen, H.M. Soluble and cellular markers of $T$ cell activation in patients with pulmonary sarcoidosis. Am Rev Resp Dis, in press.

13. Hintzen, R.Q., de Jong, R., Hack C.E., Chamuleau, M., de Vries, E.F.R, den Berge, J.J.M., Borst, J., van Lier, R.A.W. A soluble form of the human T-cell differentiation antigen $\mathrm{CD} 27$ is released after triggering of the TCR/CD3 complex. J Immunol 1991, 147, 29.

14. Hintzen, R.Q., van Lier, R.A.W, Kuijpers, K.C., Baars, P.A., Schaasberg, W., Lucas, C.J., Polman, C.H. Elevated levels of a soluble form of the $\mathrm{T}$ cell activation antigen $\mathrm{CD} 27$ in cerebrospinal fluid of multiple sclerosis patients. J Neuroimmunol 1991, 35, 211.

15. Chamuleau, M.E.D., ten Berge, J.J.M., Schellekens, P.T.A., Wilmink, J.M., Hintzen, R.Q., van Lier, R.A.W. Serum levels of soluble CD27 in renal transplant recipient. Transplantation 1992, 54, 932.

16. Hintzen, R.Q., de Jong, R., Lens, S.M.A., Brouwer, M., Baars, P., van Lier, R.A.W. Regulation of CD27 expression in subsets $T$ lymphocytes. J Immunol 1993, 151, 2426.

17. Rivero, S.J., Diaz-Jouanen, E., Alarcon-Segovia, D. Lymphopenia in systemic lupus erythematosus: clinical diagnostic and prognostic significance. Arthritis Rheum 1978, 21, 295-305.
18. Winfield, J.B., Winchester, R.J., Kunkel, H.G. Association of cold reactive antilymphocyte antibodies with lymphopenia in systemic lupus erythematosus. Arthritis Rheum 1975, 18, 587-594.

19. Tan, E.M., Cohen, A.S., Fries, J.F., Masi, A.T., Mc Shane, D.J., Rothfield, N.F., Schaller, J.G., Talal, N., Winchester, R.J. The 1982 revised criteria for the classification of systemic lupus erythematosus. Arthritis Rheum 1982, 25, 1271-1277.

20. Swaak, A.J.G., Groenwold, J., Aarden, L.A., Feltkamp, T.E.W. Detection of anti-dsDNA as a diagnostic tool. Ann Rheum Dis 1981, $40,45-49$.

21. Swaak, A.J.G., Groenwold, J., Bronsveld, W. Predictive value of complement profiles and anti-dsDNA in systemic lupus erythematosus. Ann Rheum Dis 1986, 45, 359-366. 22.Kassan, S.S., Lockskin, M.D. Central nervous system lupus erythematosus: the need for classification. Arthritis Rheum 1979, 22, 1382-1385.

23. Bonfa, E., Golombek, S.J., Lee, D.K., Skelly, S., Weissback, H., Brot, N., Elkon, K.B. Association between lupus psychosis and anti-ribosomal protein antibodies. New Eng J Med 1987, 317, 265 271.

24. Campen, D.H., Horwitz, D.A., Quismario, F.D., Ehresmann, G.R., Martin, W. Serum levels of Interleukin-2 receptor and activity of rheumatic diseases characterised by immune system activation. Arthritis Rheum 1988, 31, 1358-1364.

25. Wolf, R.E., Brelsford, W.G., Hall, V.C., Adams, S.B. Cytokines and soluble Interleukin-2 receptors in rheumatoid arthritis. J Rheumatol 1992, 19, 524-528.

26. Ward, M.M., Dooley, M.A., Christenson, V.D., Pisetsky, D.S. The relationship between soluble Interleukin 2 receptor levels and antidouble stranded DNA antibody levels in patients with systemic lupus erythematosus. J Rheumatol 1991, 18, 235-240.

27. Airo, P., Bettenzioli, M., Gorla, R., Cattaneo, R. Increased concentration of soluble Interleukin-2 receptor in serum of patients with systemic sclerosis. Ann Rheum Dis 1991, 50, 270-271.

28. Raziuddin, S., Al-Janadi, W.A., Al-Wabel, A.A. Soluble Interleukin-2 receptor levels in serum and its relationship to T-cell abnormality and clinical manifestations of the disease in patients with Systemic Lupus Erythematosus. J Rheumatol 1991, 18, 831-836.

29. Seth, K.K., Nahei. Elevated titers of cell-free Interleukin-2 receptor in serum and cerebrospinal fluid specimens of patients with acquired immunodeficiency syndrome. Immunol Lett 1986, 13, 179 184.

30. Turg, K.S.K., Kriland, E., Matznei, P. Soluble serum Interleukin-2 receptor levels in leprosy patients. Clin Exp Immunol 1987, 69, 10 15.1

Received: 7 October 1993;

Revision-accepted: 26 August 1994

Correspondence to: A.J.G. SWAAK, MD, PRD Dept. of Rheumatology, Dr. Daniel den Hoed Kliniek, Groene Hilledijk 301, 3075 EA Rotterdam, THE NETHERLANDS. 